\title{
Surgical or endovascular management of ruptured intracranial aneurysms: an agreement study
}

\author{
Tim E. Darsaut, MD, MSc, ${ }^{1}$ Robert Fahed, MD, MSc, ${ }^{2}$ R. Loch Macdonald, MD, PhD, ${ }^{3}$ \\ Adam S. Arthur, MD, MPH, ${ }^{4}$ M. Yashar S. Kalani, MD, PhD, ${ }^{5}$ Fuat Arikan, MD, PhD, ${ }^{6}$ \\ Daniel Roy, MD, ${ }^{7}$ Alain Weill, MD, MSc, ${ }^{7}$ Alain Bilocq, MD, ${ }^{8}$ Jeremy L. Rempel, MD, ${ }^{9}$ \\ Michael M. Chow, MD, MPH, ${ }^{1}$ Robert A. Ashforth, MD, ${ }^{9}$ J. Max Findlay, MD, PhD, ${ }^{1}$ \\ Luis H. Castro-Afonso, MD, PhD, ${ }^{10}$ Miguel Chagnon, PhD, ${ }^{11}$ Guylaine Gevry, BSc, ${ }^{12}$ and \\ Jean Raymond, $\mathbf{M D}^{7}$
}

${ }^{1}$ Division of Neurosurgery, Department of Surgery, Mackenzie Health Sciences Centre, University of Alberta Hospital, Edmonton, Alberta, Canada; ${ }^{2}$ Department of Interventional Neuroradiology, Fondation Rothschild Hospital, Paris, France; ${ }^{3}$ Division of Neurosurgery, Department of Surgery, St. Michael's Hospital, University of Toronto, Ontario, Canada; ${ }^{4 D e p a r t m e n t}$ of Neurosurgery, Semmes-Murphey Neurologic and Spine Clinic, University of Tennessee Health Sciences Center, Memphis, Tennessee; ${ }^{5}$ Departments of Neurosurgery, Neurology and Neuroscience, University of Virginia School of Medicine, Charlottesville, Virginia; ${ }^{6}$ Department of Neurosurgery and Neurotraumatology and Neurosurgery Research Unit (UNINN), Vall d'Hebron University Hospital, Universitat Autònoma de Barcelona, Spain; ${ }^{7}$ Service of Neuroradiology, Department of Radiology, Centre Hospitalier de l'Université de Montréal (CHUM); ${ }^{8}$ Service of Neurosurgery, Centre Hospitalier Régional de Trois-Rivières, Québec; ' Department of Radiology \& Diagnostic Imaging, Mackenzie Health Sciences Centre, University of Alberta Hospital, Edmonton, Alberta, Canada; ${ }^{10}$ Division of Interventional Neuroradiology, Department of Internal Medicine, University of São Paulo, Ribeirao Preto, Brazil; ${ }^{11}$ Department of Mathematics and Statistics, Université de Montréal; and ${ }^{12}$ Research Centre, Interventional Neuroradiology Laboratory, Centre Hospitalier de l'Université de Montréal (CHUM), Québec, Canada

OBJECTIVE Ruptured intracranial aneurysms (RIAs) can be managed surgically or endovascularly. In this study, the authors aimed to measure the interobserver agreement in selecting the best management option for various patients with an RIA.

METHODS The authors constructed an electronic portfolio of 42 cases of RIA in which an angiographic image along with a brief clinical vignette for each patient were displayed. Undisclosed to the responders was that the RIAs had been categorized as International Subarachnoid Aneurysm Trial (ISAT) (small, anterior-circulation, non-middle cerebral artery location, $n=18$ ) and non-ISAT ( $n=22$ ) aneurysms; the non-ISAT group also included 2 basilar apex aneurysms for which a high number of endovascular choices was expected. The portfolio was sent to 132 clinicians who manage patients with RIAs and circulated to members of an American surgical association. Judges were asked to choose between surgical and endovascular management, to indicate their level of confidence in the choice of treatment on a quantitative 0-10 scale, and to determine whether they would include the patient in a randomized trial in which both treatments are compared. Eleven clinicians were asked to respond twice at least 1 month apart. Responses were analyzed using kappa statistics.

RESULTS Eighty-five clinicians (58 cerebrovascular surgeons, 21 interventional neuroradiologists, and 6 interventional neurologists) answered the questionnaire. Overall, endovascular management was chosen more frequently $(n=2136$ [59.8\%] of 3570 answers). The proportions of decisions to clip were significantly higher for non-ISAT (50.8\%) than for ISAT $(26.2 \%$ ) aneurysms ( $p=0.0003)$. Interjudge agreement was only fair (kappa $0.210,95 \% \mathrm{CI} 0.158-0.276$ ) for all cases and judges, despite high confidence levels (mean score $>8$ for all cases). Agreement was no better within subgroups of clinicians with the same specialty, years of experience, or location of practice or across capability groups (abil-

ABBREVIATIONS BRAT = Barrow Ruptured Aneurysm Trial; ISAT = International Subarachnoid Aneurysm Trial; $M C A=$ middle cerebral artery; RCT = randomized controlled trial; RIA = ruptured intracranial aneurysm.

SUBMITTED October 23, 2017. ACCEPTED January 19, 2018.

INCLUDE WHEN CITING Published online July 13, 2018; DOI: 10.3171/2018.1.JNS172645. 
ity to clip or coil, or both). When agreement was defined as $>80 \%$ of responders choosing the same option, agreement occurred for only 7 of 40 cases, all of which were ISAT aneurysms, for which coiling was preferred.

CONCLUSIONS Agreement between clinicians regarding the best management option was infrequent but centered around coiling for some ISAT aneurysms. Surgical clipping was chosen more frequently for non-ISAT aneurysms than for ISAT aneurysms. Patients with such an aneurysm might be candidates for inclusion in randomized trials.

https://thejns.org/doi/abs/10.3171/2018.1.JNS172645

KEYWORDS ruptured aneurysms; endovascular treatment; surgical clipping; agreement study; vascular disorders

$\mathrm{T}$ HE International Subarachnoid Aneurysm Trial (ISAT) was a turning point in modern neurosurgical history. ${ }^{9}$ The ISAT compared surgical clipping and endovascular coiling of ruptured intracranial aneurysms (RIAs) and showed an absolute $7.4 \%$ increase in good clinical outcomes (modified Rankin Scale score < 3) at 1 year for patients treated with endovascular coiling. Because the ISAT was a pragmatic trial, a proper interpretation of results was that coiling should be first-line treatment for patients with the sort of aneurysms included in the study (i.e., those with World Federation of Neurosurgical Societies [WFNS] grade 1 or $2^{15}$ small anterior-circulation aneurysms that were treatable by simple coiling at that point in time [1994-2002]), which represents a small fraction (2143 of 9559 [22.4\%]) of the patients who were screened. If aneurysms favorable for coiling were selected preferentially in the ISAT, then data from that study cannot inform us of how best to treat many other patients with an RIA. ${ }^{2}$ This belief is supported by the high proportion (64 of 170 [38\%]) of crossovers from the coiling to the clipping arm in the Barrow Ruptured Aneurysm Trial (BRAT), a different prerandomized trial that also compared clipping and coiling for RIAs. ${ }^{8}$ Although evidence from randomized trials of superiority of endovascular treatment for some RIAs exists, the technique has shortcomings, such as conferring a higher angiographic recurrence rate, which can translate into a higher risk of future subarachnoid hemorrhage. ${ }^{10}$ Technological advances, including new coils, balloons, stents, and flow diverters, might enable treatment of a wider spectrum of lesions than at the time of the ISAT, but no evidence exists to support the use of such practices over surgical clipping. For all we know, and considering the risk of recurrence with endovascular treatment, clipping might still be best for some RIAs outside the realm of what was included in the ISAT, such as those with an atypical morphology, a wide neck, or a larger size, or when treatment is thought to require an endovascular device that was not available at that time. For many patients with an RIA, the question of what the best treatment is remains unanswered. To manage patients optimally despite such uncertainty, the ISAT-2 was launched, ${ }^{1}$ because the best treatment cannot be discovered by analyzing expert opinions alone but also by testing treatment options as they are practiced in the context of a randomized trial. Nevertheless, clinical trials are conducted more easily when the expert community does not agree about which treatment is best. In this study, we investigated decision making among experts involved in the management of patients with an RIA. We studied the interrater agreement between various experts regarding the best treatment of 2 types of RIAs, that is, those that were well represented in the ISAT (ISAT aneurysms) and those that were not (non-ISAT aneurysms).

\section{Methods}

This study was prepared and is being reported in accordance with the Guidelines for Reporting Reliability and Agreement Studies (GRRAS). ${ }^{5}$

\section{Patients}

An electronic portfolio of 42 anonymized patients with an RIA was prepared. The portfolio included an angiographic image of the aneurysm as well as a fictitious patient age and WFNS subarachnoid hemorrhage score. The number of cases was selected by 2 authors (T.E.D. and J.R.), who used practical considerations (to avoid responder fatigue) while recognizing that a minimum of 24 cases would be necessary to provide meaningful statistical results. $^{3}$

For each case, the clinicians were asked to select between endovascular or surgical treatment, rate their certainty regarding their choice on a scale from 0 to 10 , and indicate whether they would offer that patient participation in a randomized trial in which clipping and coiling would be compared. Undisclosed to those polled was that cases in the portfolio were divided among the following 2 predefined subgroups: ISAT aneurysms $(n=18)$, composed of small (7 mm or less) anterior-circulation non-middle cerebral artery (MCA) aneurysms, and non-ISAT aneurysms, which included all other aneurysms $(\mathrm{n}=22)$ plus 2 control aneurysms located at the basilar apex (for which a high frequency of endovascular choices was expected). Twentytwo (52\%) of the presented aneurysms were selected from the ISAT-2 study, a trial in which clipping and coiling for RIAs that were poorly represented in the initial ISAT trial were compared. The complete Questionnaire is available online (see Supplemental Information).

\section{Clinicians}

The portfolio was emailed to 132 clinicians who treat RIAs and circulated to members of the cerebrovascular section of the American Association of Neurological Surgeons (AANS) (which included 629 inscriptions). A completed survey was obtained from $85(11 \%)$ responders who provided demographic information but were assured of their anonymity. Included were 58 cerebrovascular surgeons, 36 of whom had been cross-trained (i.e., able to deliver both surgical and endovascular care), 21 interventional neuroradiologists, and 6 interventional neurologists. The responders were from the United States $(n=36)$, Europe 
TABLE 1. Characteristics of the aneurysms and patients included in the portfolio and in the ISAT-1 and non-ISAT-1 subgroups

\begin{tabular}{|c|c|c|c|}
\hline Variable & Overall & ISAT Group & $\begin{array}{l}\text { Non-ISAT } \\
\text { Group }\end{array}$ \\
\hline No. of cases & 42 & 18 & 24 \\
\hline $\begin{array}{l}\text { Age in yrs (mean } \\
\text { [range]) }\end{array}$ & $58(34-86)$ & $56.8(45-73)$ & $60.1(34-86)$ \\
\hline Female sex (no. [\%]) & $26(62)$ & $11(61)$ & $15(63)$ \\
\hline $\begin{array}{l}\text { Aneurysm size in mm } \\
\text { (mean [range]) }\end{array}$ & $9.3(1.5-52)$ & $7.2(4-14)$ & $10.5(1.5-52)$ \\
\hline $1-3 \mathrm{~mm}(\mathrm{n})$ & 5 & 1 & 4 \\
\hline $4-7 \mathrm{~mm}(\mathrm{n})$ & 24 & 11 & 13 \\
\hline 8-14 mm (n) & 10 & 6 & 4 \\
\hline$\geq 15$ mm (n) & 3 & 0 & 3 \\
\hline \multicolumn{4}{|l|}{ Location } \\
\hline $\mathrm{AC}(\mathrm{n}[\%])$ & $38(90)$ & 18 & 20 \\
\hline $\begin{array}{r}\mathrm{PCoA} / \mathrm{AChA} / \mathrm{ca}- \\
\text { rotid terminus }\end{array}$ & 9 & 8 & 1 \\
\hline $\mathrm{ACoA}$ & 8 & 8 & 0 \\
\hline MCA & 17 & 0 & 17 \\
\hline $\begin{array}{l}\text { Various other } \\
\text { AC locations }\end{array}$ & 4 & 2 & 2 \\
\hline $\mathrm{PC}(\mathrm{n}[\%])$ & $4(10)$ & 0 & 4 \\
\hline Basilar apex & 2 & 0 & 2 \\
\hline PICA & 2 & 0 & 2 \\
\hline
\end{tabular}

$\mathrm{AC}=$ anterior circulation; $\mathrm{ACh} \mathrm{A}=$ anterior choroidal artery; $\mathrm{ACO} \mathrm{A}=$ anterior communicating; $\mathrm{PC}=$ posterior circulation; $\mathrm{PCoA}=$ posterior communicating; PICA = posterior inferior cerebellar artery

$(n=23)$, Canada $(n=19)$, Brazil $(n=6)$, or Japan $(n=1)$ and had been in practice for $0-5$ years $(n=18), 6-10$ years $(n=29)$, or more than 10 years $(n=38)$. Eleven judges were asked to answer the questionnaire twice, more than 1 month apart, to enable intraobserver evaluations.

\section{Statistical Analysis}

Interrater and intrarater agreement regarding choice of treatment was assessed using Fleiss kappa statistics with $95 \%$ bias-corrected confidence intervals obtained by 1000 bootstrap resampling. Kappa values were interpreted in terms of strength of agreement according to Landis and $\operatorname{Koch}^{6}$ (0-0.2, slight; 0.21-0.4, fair; 0.41-0.6, moderate; and $0.61-0.8$, substantial). Confidence in decision making along a scale of $0-10$ was analyzed with ANOVA and differences between proportions using the Fisher exact test. All analyses were performed by a statistician (M.C.) using Stata IC 12.0 (StataCorp) and a significance level of 5\%.

\section{Results \\ Portfolio}

Patient and aneurysm characteristics for the portfolio as a whole, and divided among ISAT and non-ISAT aneurysms, are listed in Table 1. Examples of RIA cases taken from the portfolio, with representative results, are presented in Figs. 1 and 2. The complete Questionnaire and
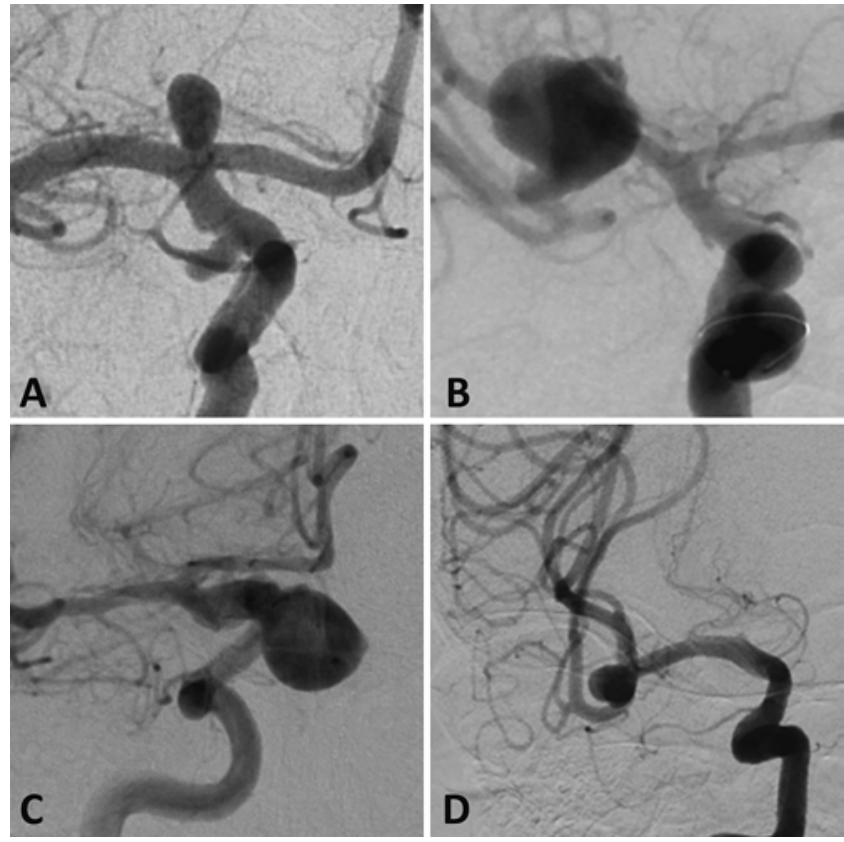

FIG. 1. Angiographic examples of cases from the portfolio. A: Image obtained in a 74-year-old woman (case 12) with a 5-mm carotid terminus aneurysm $(87.1 \%$ of the clinicians selected endovascular coiling, mean confidence score 9.1). B: Image from a 58-year-old man (case 18) with a $12-\mathrm{mm}$ MCA bifurcation aneurysm $(76.5 \%$ of the clinicians selected surgery, mean confidence score 8.6). C: This case, of a 14-mm paraclinoid aneurysm in a 73-year-old woman (case 40), had very high agreement $(95.3 \%$ of the clinicians selected endovascular treatment, mean confidence score 9.3). D: This 5-mm MCA aneurysm in a 62-year-old woman (case 27 ) had the lowest agreement among the experts $(50.6 \%$ of the clinicians selected surgery, mean confidence score 8.4).

the proportions of expert votes for each case are available online (see Supplemental Information).

\section{Responses}

The choice to coil was more common $(n=2136$ [59.8\%]) than the choice to clip $(n=1434$ [40.2\%]). The proportion of decisions to clip was significantly higher for nonISAT (50.8\%) than that for ISAT (26.2\%) aneurysms ( $\mathrm{p}=$ 0.0003 ) (Fig. 3). The proportion of responders who chose clipping was significantly higher among those 54 clinicians who were practicing in North America (1010 of 2251 [44.9\%, 95\% CI 42.8\%-47.0\%]) than among the 24 practicing in Europe (333 of 997 [33.4\%, 95\% CI 30.5\%-36.4]) $(\mathrm{p}<0.0001)$. The numbers of times that the clinicians responded that they would be willing to allocate treatments randomly were similar for ISAT (848 of $1524[55.6 \%, 95 \%$ CI $53.1 \%-58.2 \%]$ ) and for non-ISAT (1080 of 2034 [53.1\%, 95\% CI 50.9\%-55.3\%]) cases.

The overall agreement between all cases and judges on the best management of the patients with an RIA was only fair (kappa $=0.210,95 \%$ CI 0.158-0.276) (Table 2). Agreement did not improve when the respondents were grouped according to specialty; surgeons disagreed with each other, as did neuroradiologists and neurologists, and each group disagreed with the other. Having greater experience managing RIAs did not improve agreement; the most experienced clinicians ( $>10$ years of practice) had 
poor agreement among themselves, whereas those who had been managing aneurysms for $0-5$ or 6-10 years had fair agreement with each other. Considering clinicians who shared a type of practice (those who can only coil compared to those who can only clip compared to those who can perform both procedures) did not improve agreement, nor did grouping responders according to their geographical consideration. Kappa values were uniformly low for those who were considered to have an ISAT aneurysm (kappa $=0.100,95 \%$ CI 0.037-0.183) and for those with a non-ISAT aneurysm (kappa $=0.189,95 \%$ CI 0.100-0.307).

When the same judges considered the same cases at least 1 month later, the intrajudge agreement was above "substantial" for 8 of 11 judges and ranged from fair to almost perfect (kappa $=0.356$ to 0.869 [mean $0.636 \pm 0.188]$ ).

Endovascular management was selected almost unanimously for the 2 control basilar apex lesions (a 4-mm aneurysm, $100 \%$ of respondents selected endovascular treatment, and a 5-mm aneurysm, 96.5\% selected endovascular treatment). A $14-\mathrm{mm}$ paraclinoid aneurysm garnered $95.3 \%$ of the votes for endovascular treatment. The 4 aneurysms that obtained the highest proportions of votes for surgical management were all located on the MCA (12 $\mathrm{mm}$ [76.5\%], $4 \mathrm{~mm}$ [72.9\%], $1.5 \mathrm{~mm}$ [72.9\%], and $2 \mathrm{~mm}$ [72.9\%]). Eight cases (19.0\%, 95\% CI 10.0\%-33.3\%), 2 ISAT and 6 non-ISAT aneurysms, 5 of which were MCA aneurysms, received a near-equal (within 40\%-60\%) proportion of votes for surgical or endovascular management (Fig. 3).

If agreement was said to exist when at least $80 \%$ of the experts selected the same treatment option, then there was agreement for 9 (21\%) of the 42 cases (the 2 basilar apex control aneurysms, the $14-\mathrm{mm}$ paraclinoid aneurysm, and 6 small anterior-circulation aneurysms), all of which were judged best treated with endovascular methods. If the threshold level required for agreement were lowered to $70 \%$, then the number of cases for which agreement existed would increase to $27(64 \%)$ of the 42 cases.

Self-assessed certainty levels correlated with agreement; when judges indicated that they felt less certain about a case, more disagreement was found (rho $=0.653$, $\mathrm{p}=0.01$ ). However, even in the presence of maximal disagreement, mean certainty levels were uniformly high (> 8 in all cases). The degrees of certainty were not different for surgeons, radiologists, or neurologists and did not vary according to years of experience.

Endovascular management was the preferred option for $17(94.4 \%)$ of 18 ISAT aneurysms and was selected by more than $70 \%$ of the raters in $13(72.2 \%)$ of 18 patients. Yet, at least $50 \%$ of the raters were willing to include 15 $(83.3 \%)$ of these 18 patients in a trial. Surgical management was the preferred treatment decision for $14(58.3 \%)$ of 24 non-ISAT aneurysms. At least $50 \%$ of the physicians were willing to offer trial participation to $16(66.7 \%)$ of the 24 patients with a non-ISAT aneurysm (Fig. 3). Overall, other than the 2 patients with a basilar apex aneurysm (the controls), every patient was considered suitable for inclusion in a randomized trial by at least $39 \%$ of the responders (range 39.3\%-70.6\%) (Fig. 3). A majority of the clinicians were willing to include the patient in a randomized trial that would compare clipping and coiling in 31 of 42 cases
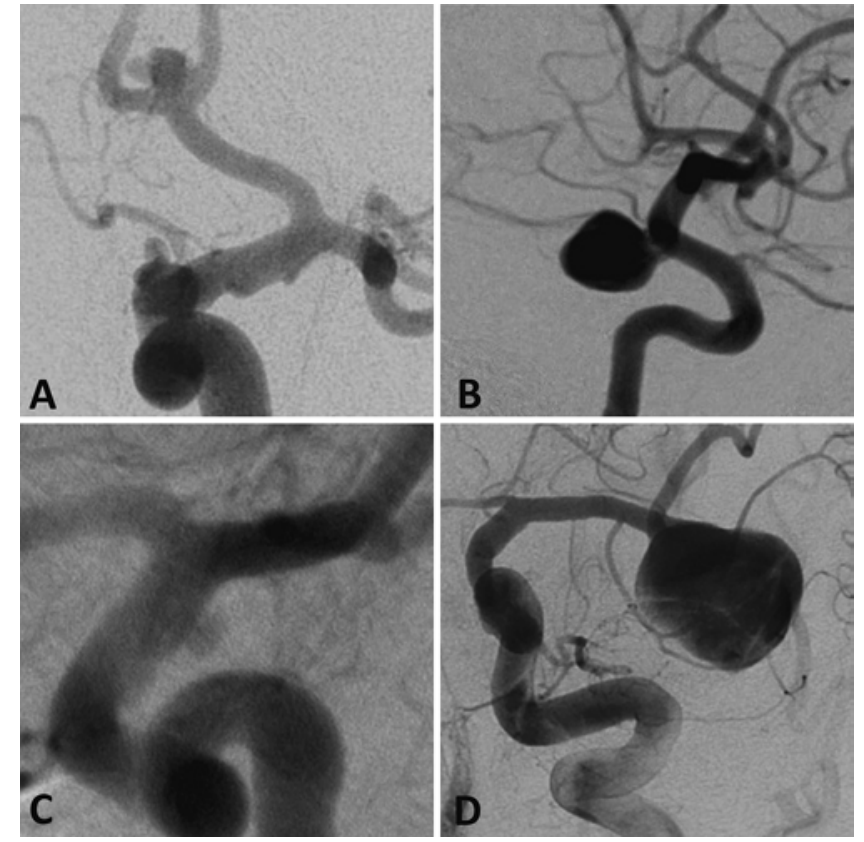

FIG. 2. Angiographic examples of cases of ISAT aneurysms (A and B), for which high agreement was found, and non-ISAT aneurysms ( $C$ and D), for which uncertainty remains. Shown are a 4-mm anterior communicating artery aneurysm (case 1, A) and a 7-mm posterior communicating aneurysm (case 22, B); $81.2 \%$ of the respondents selected endovascular management for both of these aneurysms. Also shown are a 2-mm posterior communicating artery aneurysm (case 3, C), for which $54.1 \%$ selected endovascular management, and a $36-\mathrm{mm}$ MCA aneurysm (case $36, \mathrm{D}$ ), for which $55.3 \%$ selected surgical management.

(73.8\%, 95\% CI 58.0\%-86.1\%). We found no difference in this willingness according to specialist training background or years of experience.

\section{Discussion}

The results of this study show that clinicians disagree on the best management of RIAs in a substantial number of patients. Although individual clinicians were more consistent with themselves and they all expressed a high level of certainty for most decisions, agreement in decision making was no better between clinicians of the same background, experience, or clipping and/or coiling ability.

The survey included many aneurysms that were not well represented in the original ISAT study, including 17 (40\%) of 42 at the MCA location. Coiling was chosen more frequently than clipping for small non-MCA anterior-circulation aneurysms, and 6 of the 7 noncontrol cases for which $>80 \%$ agreement existed were of such aneurysms. However, even within the ISAT subgroup of RIAs, agreement remained below the substantial level.

Concerns that surgical clipping might slowly but inevitably disappear are growing. 1,7 However, the results of our study show that in many cases clipping remains the preferred option for many clinicians, including those without a surgical training background. Surveying expert opinions on the management of individual cases cannot be used as evidence regarding which is best, and it was certainly not 


\section{- Randomization EEVT EClipping}
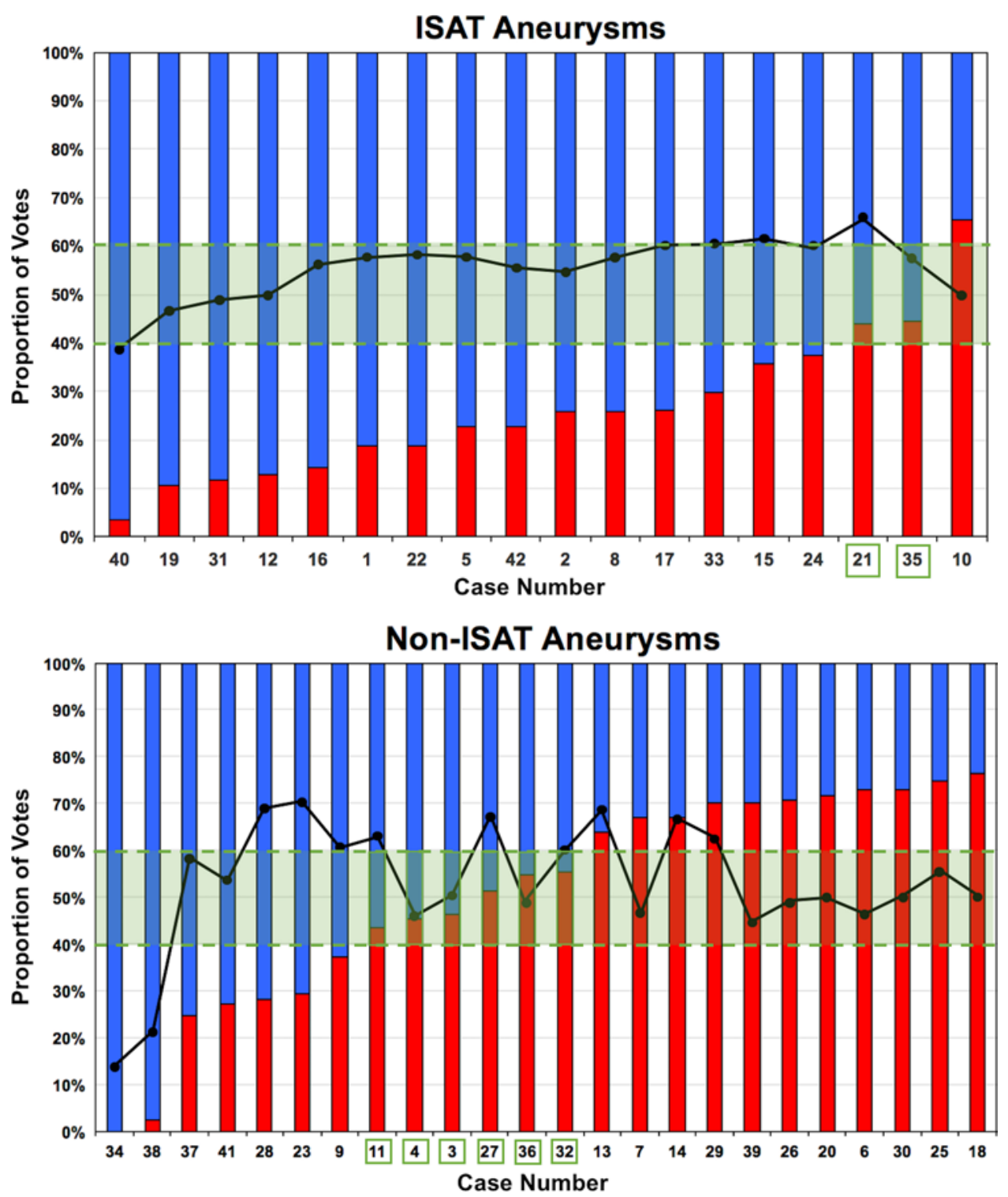

FIG. 3. Proportions of votes for surgical management and for endovascular treatment (EVT) for each case of ISAT (upper) and non-ISAT (lower) aneurysms, along with the proportion of clinicians willing to include the patient in an RCT. Note the lower proportion of ISAT aneurysms that received surgical votes and the greater number of non-ISAT aneurysm cases that had approximately equivalent numbers of votes for surgical management and for EVT (within the $40 \%-60 \%$ shaded bar).

our goal with this work. All physicians have some degree of bias in their management decisions, one way or another, based on their training and experience,,$^{14}$ which might have contributed to the different proportions of choices for clipping by North American and European responders that we observed. We believe that the lack of agreement on the best course of action is caused by the paucity of evidence supporting the benefits of clipping in the management of RIAs. We do have evidence from the ISAT that coiling can lead to better outcomes in some patients, but the generalizability of those results to all patients with an RIA has been contested. ${ }^{12}$ Another trial that used prerandomization also supported coiling over clipping, but nearly $40 \%$ of the cases allocated to coiling were crossed over to clipping. ${ }^{13}$ Although results of the BRAT, along with those from our survey, seem to tell us that clipping might still be best for a substantial number of patients, neither study has provided evidence regarding the kind of patients who should be treated with clipping. We have complained previously that too often, randomized controlled trial (RCTs) are stopped prematurely and that we should learn to pursue RCTs for subgroups of patients for whom results of the overall group do not necessarily apply. When uncertainty for a subgroup exists, we believe that those patients are still best managed within the context of a care trial. ${ }^{1,11}$ The results of our study, in which wide discrepancies in management choices were found, suggest that many patients with an RIA could be candidates for the ISAT- 2 trial. 
TABLE 2. Interobserver agreement according to experience, specialty, and ability*

\begin{tabular}{cc}
\hline Responders $(\mathrm{n}=85)$ & Kappa Value $(95 \% \mathrm{Cl})$ \\
\hline Experience & \\
\hline $0-5$ yrs & $0.203(0.138-0.293)$ \\
\hline $6-10$ yrs & $0.266(0.206-0.335)$ \\
\hline$>10$ yrs & $0.183(0.131-0.265)$ \\
\hline Specialty & \\
\hline Cerebrovascular surgery & $0.207(0.147-0.288)$ \\
\hline Interventional neuroradiology & $0.234(0.174-0.309)$ \\
\hline Interventional neurology & $0.250(0.118-0.388)$ \\
\hline Coiling ability & $0.244(0.190-0.312)$ \\
\hline Clipping ability & $0.218(0.135-0.339)$ \\
\hline Clip and coil ability & $0.258(0.197-0.331)$ \\
\hline Location of practice & \\
\hline North America & $0.218(0.210-0.226)$ \\
\hline Europe & $0.195(0.176-0.213)$ \\
\hline Overall & $0.210(0.158-0.276)$ \\
\hline
\end{tabular}

${ }^{*}$ Ability to clip, coil, or both.

The notion of community equipoise was introduced to replace the inappropriate notion of individual equipoise. ${ }^{4}$ Too narrowly conceived or even community equipoise cannot work, as shown by the small number of cases (8 [20\%]) that would have been included in a trial if equipoise were defined as a $40 \%-60 \%$ window of choices, compared to the number of patients for whom a majority of raters would have offered trial participation (31 [73.8\%]). The relationship between treatment choice, confidence level, and trial participation is admittedly weak at best (Fig. 3). In our view, and even though the notion of community equipoise can help predict difficulties with recruitment, it is ethically and scientifically erroneous, because it remains a notion that puts unwarranted conditions on trial participation. Just as the truth regarding which treatment is best cannot be determined by voting, the question as to who should be included in the trial should not be determined by voting. We maintain that, once a trial has been conceived in the best interest of patients, clinicians should offer participation in that trial whenever they consider using a treatment that is not supported by Level 1 evidence. ${ }^{11}$

There are many limitations to this study. Responders were a small group of self-selected clinicians who might have chosen to answer the questionnaire because of some unknown bias for or against a particular type of treatment. Individual decisions were likely influenced by not only aneurysm and patient characteristics but also a selfevaluation of skills and capacities, which, when coupled with technological innovations and research progress, means that decision making is a process that is in constant evolution. Agreement studies such as this one do not attempt to capture an index or variable that is representative of a population ${ }^{5}$; they assess only whether judgments between raters are reproducible. The number of endovascular choices, however, is certainly correlated to the number of responders who were routinely using coiling in their clinical practice; as a consequence, the absolute number of endovascular choices was influenced by the proportion of coilers among the responders (57 of 85 [67\%]). The selection of cases for the portfolio deliberately included the cases of some patients taken from the ISAT-2 trial; thus, the distribution of cases is not expected to be considered a "routine" series of RIAs. The selection of different cases might have produced different results. Decisions to coil difficult aneurysms can be simplified by reviewing multiple angiographic projections of the aneurysm neck, but in this study, we presented only 1 image per case for ease and clarity of presentation. We also chose to include only cases in which catheter angiography had been performed before treatment, which might have skewed case selection for the portfolio.

Last, completing an electronic survey and caring for real patients are very different activities. The degree to which responders imagined they were dealing with serious decisions can only be surmised.

\section{Conclusions}

In this study, agreement regarding the best management of patients with an RIA was found in only a small proportion of cases. Choices for surgical management remain high for aneurysms considered to not be well represented in the ISAT. Patients with such an aneurysm are potential candidates for ongoing randomized trials.

\section{References}

1. Darsaut TE, Jack AS, Kerr RS, Raymond J: International Subarachnoid Aneurysm Trial - ISAT part II: study protocol for a randomized controlled trial. Trials 14:156, 2013

2. Darsaut TE, Raymond J: Last call for clipping aneurysms? J Neurosurg 124:1130-1131, 2016 (Letter)

3. Donner A, Rotondi MA: Sample size requirements for interval estimation of the kappa statistic for interobserver agreement studies with a binary outcome and multiple raters. Int $\mathbf{J}$ Biostat 6:31, 2010

4. Freedman B: Equipoise and the ethics of clinical research. $\mathbf{N}$ Engl J Med 317:141-145, 1987

5. Kottner J, Audigé L, Brorson S, Donner A, Gajewski BJ, Hróbjartsson A, et al: Guidelines for Reporting Reliability and Agreement Studies (GRRAS) were proposed. J Clin Epidemiol 64:96-106, 2011

6. Landis JR, Koch GG: The measurement of observer agreement for categorical data. Biometrics 33:159-174, 1977

7. Macdonald RL: Editorial: Clip or coil? Six years of follow-up in BRAT. J Neurosurg 123:605-607, 2015

8. McDougall CG, Spetzler RF, Zabramski JM, Partovi S, Hills NK, Nakaji P, et al: The Barrow Ruptured Aneurysm Trial. J Neurosurg 116:135-144, 2012

9. Molyneux A, Kerr R, Stratton I, Sandercock P, Clarke M, Shrimpton J, et al: International Subarachnoid Aneurysm Trial (ISAT) of neurosurgical clipping versus endovascular coiling in 2143 patients with ruptured intracranial aneurysms: a randomised trial. Lancet 360:1267-1274, 2002

10. Molyneux AJ, Birks J, Clarke A, Sneade M, Kerr RS: The durability of endovascular coiling versus neurosurgical clipping of ruptured cerebral aneurysms: 18 year follow-up of the UK cohort of the International Subarachnoid Aneurysm Trial (ISAT). Lancet 385:691-697, 2015

11. Raymond J, Darsaut TE, Altman DG: Pragmatic trials can be designed as optimal medical care: principles and methods of care trials. J Clin Epidemiol 67:1150-1156, 2014

12. Raymond J, Kotowski M, Darsaut TE, Molyneux AJ, Kerr 
RS: Ruptured aneurysms and the International Subarachnoid Aneurysm Trial (ISAT): what is known and what remains to be questioned. Neurochirurgie 58:103-114, 2012

13. Spetzler RF, McDougall CG, Zabramski JM, Albuquerque FC, Hills NK, Russin JJ, et al: The Barrow Ruptured Aneurysm Trial: 6-year results. J Neurosurg 123:609-617, 2015

14. Tanweer O, Wilson TA, Kalhorn SP, Golfinos JG, Huang PP, Kondziolka D: Neurosurgical decision making: personal and professional preferences. J Neurosurg 122:678-691, 2015

15. Teasdale GM, Drake CG, Hunt W, Kassel N, Sano K, Pertuiset B, et al: A universal subarachnoid hemorrhage scale: report of a committee of the World Federation of Neurosurgical Societies. J Neurol Neurosurg Psychiatry 51:1457, 1988

\section{Disclosures}

Dr. Arthur has ownership in Cerebrotech, Serenity, Magneto, Synchron, Bendit, and Neurogami and is a consultant for Medtronic, Penumbra, Johnson \& Johnson, Microvention, Stryker, Leica, and Scientia.

\section{Author Contributions}

Conception and design: Raymond, Darsaut, Gevry. Acquisition of data: Raymond, Darsaut, Macdonald, Arthur, Kalani, Arikan,
Roy, Weill, Bilocq, Rempel, Chow, Ashforth, Findlay, CastroAfonso. Analysis and interpretation of data: Raymond, Darsaut, Chagnon. Drafting the article: Raymond, Darsaut, Fahed. Critically revising the article: Raymond, Darsaut, Fahed, Macdonald, Arthur, Kalani, Arikan, Roy, Weill, Bilocq, Rempel, Chow, Ashforth, Findlay, Castro-Afonso, Chagnon. Reviewed submitted version of manuscript: Raymond, Darsaut, Fahed, Macdonald, Arthur, Kalani, Arikan, Roy, Weill, Bilocq, Rempel, Chow, Ashforth, Findlay, Castro-Afonso, Chagnon. Approved the final version of the manuscript on behalf of all authors: Raymond. Administrative/technical/material support: Gevry. Study supervision: Raymond, Darsaut, Gevry.

\section{Supplemental Information}

\section{Online-Only Content}

Supplemental material is available with the online version of the article.

Questionnaire. https://thejns.org/doi/suppl/10.3171/2018.1. JNS172645.

\section{Correspondence}

Jean Raymond: CHUM-Notre-Dame Hospital, Montreal, QC, Canada. jean.raymond@umontreal.ca. 